Risa Pitriani, Rika Andriyani

\title{
PENERAPAN PENDOKUMENTASIAN ASUHAN KEBIDANAN DENGAN METODE S-O-A-P PADA PRAKTIK BIDAN MANDIRI
}

\author{
Risa Pitriani ${ }^{*}$, Rika Andriyani ${ }^{2}$ \\ Prodi D III Kebidanan STIKes Hang Tuah Pekanbaru \\ *Korespondensi email : risapitriani@htp.ac.id
}

\section{ABSTRACT IMPLEMENTATION OF MIDWIFERY CARE DOCUMENTATION WITH THE S-O-A-P METHOD IN THE PRACTICE OF MANDIRI MIDWIVES}

Background: Documentation is evidence of health care that contains the activities of recording, authentic reporting, and storage of all activities related to client management that can be used to reveal actual and accountable facts. Based on the results of the preliminary study, 3 out of 5 independent practice midwives in Pekanbaru stated that they had not done the documentation correctly and consistently

Purpose: The purpose of this research is to find out the application of documentation of the SOAP method for Independent Practice Midwives in Pekanbaru. This research method has a type of quantitative research with a descriptive research design. This research was conducted under the auspices of the Pekanbaru City IBI Branch Management on 3 September - 3 November 2020. The number of samples collected was 30 midwives. The data analysis used simple descriptive univariate analysis in the form of presentation.

Results: The results of this study showed the application of documentation of the S-O-A-P method in midwifery care carried out by midwives in Pekanbaru city, 14 midwives used S-O-A-P with a percentage of 46.6 in documenting their midwifery care and there were 16 with a percentage of 53.3 midwives who did not use the S-OA-P method in midwifery care.

Conclusion: Based on the research results, the majority of independent practicing midwives have not implemented documentation using the S-O-A-P method in their midwifery care. The recording using the S-O-A-P method is stated in the Minister of Health Decree no. 938 of 2007.

Suggestion It is expected that independent practice midwives can record in every midwifery service performed, in order to achieve quality services.

Keywords: Documentation, SOAP, Independent Midwife Practice

\section{ABSTRAK}

Latar Belakang : Pendokumentasian merupakan suatu bukti pelayanan kesehatan yang berisi kegiatan pencatatan, pelaporan yang otentik dan penyimpanan semua kegiatan yang berkaitan dengan pengelolaan klien yang dapat dipergunakan untuk mengungkapkan suatu fakta aktual dan dapat dipertanggungjawabkan. Berdasarkan hasil studi pendahuluan, 3 dari 5 bidan praktik mandiri di Pekanbaru menyatakan bahwa belum melakukan pendokumentasian dengan benar dan konsisten

Tujuan : Tujuan penelitian ini untuk diketahuinya penerapan pendokumentasian metode S-O-A-P Bidan Praktik Mandiri DI Pekanbaru. Metode Penelitian ini memiliki jenis penelitian kuantitatif dengan rancangan penelitian deskriptif. Penelitian ini dilakukan di PMB yang ada di Pekanbaru pada tanggal 3 September - 3 November 2020. Teknik pengambilan sampel pada penelitin ini adalah consecutive random sampling yaitu cara pengambilan sampel yang dilakukan dengan cara memilih sampel yang memenuhi kriteria penelitian sampai kurun waktu tertentu sehingga jumlah sampel terpenuhi (Hidayat, 2009). Adapaun jumlah sampel yang telah dikumpulkan adalah sebnayak 30 orang bidan.Dalam analisis data digunakan analisa univariat secara deskriptif sederhana berupa distribusi frekuensi

Hasil : Hasil Penelitian ini didapatkan penerapan pendokumentasian metode S-O-A-P dalam asuhan kebidanan yang dilakukan bidan di kota Pekanbaru, terdapat 14 bidan yang menggunakan S-O-A-P dengan persentase 46,6 dalam mendokumentasikan asuhan kebidanan yang dilakukan nya dan terdapat 16 dengan persentase 53.3 bidan yang tidak menggunakan metode S-O-A-P dalam asuhan kebidanan.

Kesimpulan : Berdasarkan hasil penelitian mayoritas bidan praktik mandiri belum menerapkan pendokumentasian dengan metode S-O-A-P dalam asuhan kebidanannya. Pencatatan menggunakan metode SO-A-P tertuang dalam Kepmenkes no 938 tahun 2007. 


\section{JKM (Jurnal Kebidanan Malahayati),Vol 7,No.3.Juli 2021, \\ ISSN (Print) 2476-8944 ISSN (Online) 2579-762X, Hal 544-547}

Saran Diharapkan bidan praktik mandiri dapat melakukan pencatatan dalam setiap pelayanan kebidanan yang dilakukan, agar tercapai pelayanan yang berkualitas.

Kata Kunci : Pendokumentasian, SOAP, Praktik Bidan Mandiri

\section{PENDAHULUAN}

Pendokumentasian merupakan suatu bukti pelayanan kesehatan yang beris kegiatan pencatatan, pelaporan yang otentik dan penyimpanan semua kegiatan yang berkaitan dengan pengelolaan klien yang dapat dipergunakan untuk mengungkapkan suatu fakta aktual dan dapat dipertanggungjawabkan (Haslinda, 2017). Pencacatan klinis menjadi dokumen yang sangat berguna bagi bidan maupun pasien yang menerima pelayanan.(Sumiati,2018) Pendokumentasian dapat membantu bidan menjaga informasi dasar secara tertulis yang diperlukan dalam lingkungan praktek, namun pendokumentasian yang akurat dalam lingkungan pelayanan kesehatan harus terkait dengan konsep praktik yang berbasis bukti, objektif, dan tidak memihak (Aisa S, 2018)

Setiap catatan harus memberikan informasi penting yang berpotensi memandu profesional kesehatan lain dalam mentransfer asuhan, seperti yang mungkin terjadi dalam rujukan yang berorientasi masalah, rujukan keperawatan dokter untuk kondisi beresiko tinggi, atau lintas pengurusan cakupan yang sederhana antar bidan.(Bensley,2009) Dokumentasi adalah kunci memvalidasi asuhan yang berkualitas, keterampilan dokumentasi menjadi sangat penting dalam praktik kebidanan (Aisa S, 2018)

Semua bidan harus meningkatkan kewaspadaan diri yang terkait dengan pendokumentasiuan asuhan yang mereka berikan kepada para pasien mereka, terlepas seberapa banyak pasien mereka. Dokumentasi asuhan kebidanan tersebut harus mencerminkan esensi dari kebidanan: asuhan yang berorientasi pada perempuan yang difokuskan pada keunggulan dalam proses memberikan asuhan dengan perhatian terhadap hasil (Wildan M, 2008)

Salah satu format catatan yang dapat menjadi dokumentasi kebidanan adalah format catatan S-O-A-P yang tertuang dalam KepMenKes 938 tentang standar asuhan kebidanan, yakni pada standar VI. Catatan S-O-A-P Adalah metode dokumentasi paling umum yang digunakan oleh penyedia kesehatan, termasuk bidan, untuk memasukkan catatan ke rekam medis pasien. Catatan ini memungkinkan penyedia kesehatan untuk merekam dan berbagi informasi dalam format universal, sistematis, dan mudah dibaca (Aisa S, 2018)

Penggunaan catatan S-O-A-P memberikan banyak manfaat dalam pelaksanaannya, salah satunya adalah dapat membantu bidan untuk mengatur proses berpikir yang terlibat dalam asuhan pasien. Dengan berpikir secara terorganisasi, bidan dapat secara lebih baik membuat keputusan tentang asuhan pasien (Aisa $S$, 2018) Namun dalam pelaksanaanya masih terdapat bidan yang belum menggunakan S-O-A-P sebagai metode pendokumentasian.(Ariyanti,2010)

Menurut hasil penelitian Palifiana, 2016 dikabupaten Bantul, didapatkan hasil bahwa metode pendokumentasian yang dilakukan oleh bidan masih beraneka ragam seperti menggunakan Varney, S-O-A-P dan juga narasi. Selain itu hasil penelitian ini juga memberikan hasil bahwa pendokumentasian asuhan kebidanan dipengaruhi oleh tingkat pendidikan bidan ( $p$ value 0,24).(Palifiana, 2016)

Berdasarkan hasil studi pendahuluan, 3 dari 5 bidan praktik mandiri di Pekanbaru menyatakan bahwa belum melakukan pendokumentasian dengan benar dan konsisten. Berdasarkan uraian diatas maka peneliti tertarik untuk melakukan penelitian tentang "Penerapan pendokumentasian asuhan kebidanan dengan metode S-O-A-P pada Bidan praktik Mandiri di Pekanbaru".

\section{METODOLOGI PENELITIAN}

Penelitian ini memiliki jenis penelitian kuantitatif dengan rancangan penelitian deskriptif untuk melihat bagaimana penerapan pendokumentasian metode S-O-A-P oleh Bidan Praktik Mandiri di Pekanbaru. Penelitian ini dilakukan PMB yang ada di Kota Pekanbaru pada tanggal 3 September -3 November 2020. Populasi dalam penelitian ini adalah seluruh bidan praktik mandiri yang ada di kota Pekanbaru berjumlah 289 tempat. Teknik pengambilan sampel pada penelitin ini adalah consecutive random sampling yaitu cara pengambilan sampel yang dilakukan dengan cara memilih sampel yang memenuhi kriteria penelitian sampai kurun waktu tertentu sehingga jumlah sampel terpenuhi (Siyoto,2015). Adapaun jumlah sampel yang telah dikumpulkan adalah sebnayak 30 orang bidan. Dalam analisis data digunakan 
analisa univariat secara deskriptif sederhana berupa table distribusi frekuensi

\section{HASIL DAN PEMBAHASAN \\ Tabel 1. \\ Distribusi Frekuensi Pendidikan Bidan Di Kota Pekanbaru}

\begin{tabular}{lcc}
\hline Tingkat Pendidikan & Jumlah & Persentase \\
\hline D I & 1 & 3,3 \\
D III & 15 & 50 \\
D IVIS1 & 12 & 40 \\
S2 & 2 & 6,6 \\
\hline \multicolumn{1}{r}{ Jumlah } & 30 & $100 \%$ \\
\hline
\end{tabular}

Berdasarkan Tabel 1 Pendidikan bidan di Kota Pekanbaru yang terbanyak adalah D-III yaitu sebanyak 15 orang dengan persentase $50 \%$, bidan yang bependidikan D-IV sebanyak 12 orang atau $40 \%$, bidan yang berpendidikan D-I sebanyak 1 orang atau 3,3\%, sedangkan bidan yang berpendidikan S2 sebanyak 2 orang atau 3,3\%.

Tabel 2.

Penerapan Pendokumentasian Metode S-O-A-P

\begin{tabular}{lcc}
\hline \multicolumn{1}{c}{ Penerapan } & Frekuensi & Persentase \\
\hline Ya, metode S-O-A-P & 14 & 46,6 \\
Tidak, & 16 & 53,3 \\
\hline \multicolumn{1}{c}{ Jumlah } & 30 & $100 \%$ \\
\hline
\end{tabular}

Berdasarkan Tabel 2 diketahui bahwa penerapan pendokumentasian metode S-O-A-P dalam asuhan kebidanan yang dilakukan bidan di kota Pekanbaru, terdapat 14 bidan yang menggunakan S-O-A-P dalam mendokumentasikan asuhan kebidanan yang dilakukan nya dan terdapat 16 bidan yang tidak menggunakan metode S-O-A-P dalam asuhan kebidanan.

\section{PEMBAHASAN}

Berdasarkan hasil penelitian yang diperoleh bahwa dari 30 responden, terdapat 14 bidan (46,6 $\%)$ yang melakukan pendokumentasian dengan menggunakan metode S-O-A-P dan mayoritas bidan praktik mandiri ( $53,3 \%$ ) belum menerapkan pendokumentasian metode S-O-A-P dalam asuhan kebidanan. Latar oendidikan bidan mayoritas berpendidikan DIII kebidanan yakni berjumlah 15 orang $(50 \%)$ dan terdapat bidan dengan latar belakang S2 dengan jumlah 2 orang ( $6,6 \%)$

Dokumentasi kebidanan sangat penting bagi bidan dalam memberikan asuhan kebidanan.(Alimul,2008) Hal ini karena asuhan kebidanan yang diberikan kepada klien membutuhkan pencatatan dan pelaporan yang dapat digunakan sebagai acuan untuk menuntut tanggung jawab dan tanggung gugat dari berbagai permasalahan yang mungkin dialami oleh klien berkaitan dengan pelayanan yang diberikan (Wildan $M$, 2008). Menurut hukum jika sesuatu tidak didokumentasikan berarti pihak yang bertanggung jawab tidak melakukan apa yang seharusnyan dilakukan. Jika bidan tidak melaksanakan atau menyelesaikan suatau aktivitas atau mendokumentasikan secara tidak benar, dia bisa dituntut melakukan malpraktik. Dokumentasi kebidanan harus dapat dipercaya secara legal.( Ramadanty, y. 2018).

Berdasarkan Kepmenkes 938 tentang standar asuhan kebidanan, pada standar $\mathrm{VI}$ menjelaskan bahwa bidan melakukan pencatatan secara lengkap, akurat, singkat dan jelas mengenai keadaan/kejadian yang ditemukan dan dilakukan dalam memberikan asuhan kebidanan dan pencatatan ditulis dalam bentuk catatan perkembangan S-O-A-P. Namun dalam pelaksanaan nya masih banyak bidan yang tidak mendokumentasikan asuhan kebidanan yang dilakukan dengan menggunakan metode S-O-A-P. (Kepmenkes, 2007)

Menurut asumsi peneliti, pendidikan bidan yang mayoritas berpendidikan DIII yakni berjumlah 15 orang $(50 \%)$ harusnya menjadi faktor utama dalam pelaksanaan pendokumentasian S-O-A-P, hal ini sejalan dengan kompetensi yang dimiliki oleh seseoarang yang lulusan ahli madya kebidanan, yakni memiliki kemampuan yang meliputi pengetahuan, keterampilan, dan sikap dalam memberikan Pelayanan Kebidanan dan juga sudah dibekali ilmu manajemen asuhan kebidanan yang salah satu unsurnya adalah pencatatan menggunakan S-O-A-P.(Kepmenkes, 2020). Namun hal ini tidak sesuai dengan yang ditemukan dilapangan, masih terdapat bidan dengan pendidikan DII kebidanan tidak melakukan pendokumentasian metode S-O-A-P

Menurut hasil penelitian Anita tahun 2016, tentang penerapan pendokumentasian oleh bidan, hasil penelitian ini didapatkan 103 orang bidan $(53,9$ $\%$ ) yang tidak melakukan pendokumentasian S-OA-P dalam asuhan kebidanan. Dari penelitian tersebut dijelaskan bahwa terdapat beberapa faktor yang berhubungan dengan pelaksanaan pendokumentasian S-O-A-P, yakni faktor pengetahuan, faktor sikap dan pendidikan bidan. (Anita, 2016)

Penerapan pendokumentasian metode S-OA-P oleh bidan perlu mendapatkan pengawasan secara berkala oleh organisasi profesi agar kualitas 


\section{JKM (Jurnal Kebidanan Malahayati),Vol 7,No.3.Juli 2021, ISSN (Print) 2476-8944 ISSN (Online) 2579-762X, Hal 544-547}

pelayanan kebidanan semakin meningkat.(Puspita,2019) Kegiatan Pertemuan bulanan bidan dapat ditujukan untuk mengadakan diskusi tentang format dokumentasi kebidanan dan kendala yang dihadapi dalam pencatatan asuhan kebidanan. (Anggraini,2020).Hal ini juga dapat meningkatkan sikap bidan yang pada awalnya tidak mau mencatat asuhan kebidanan karena berbagai alasan, salah satu cara untuk mendorong mereka melaksanakan pendokumentasian adalah melalui pencabutan izin praktik jika tidak melakukannya (Anita, 2016)

Mengingat pentingnya sebuah pendokumentasian dalam hal ini dengan metode SO-A-P, sudah seharusmya setiap bidan dalam menjalankan praktiknya melakukan asuahan kebidanan harus ada pencatatannya. (Mertasari,2020).Apalagi pendokumentasian metode S-O-A-P ini telah diatur dalam kepmenkes no 938 tahun 2007. Namun hal ini tidak sesuai dengan yang ditemukan di lapangan. (Aryanti,2010)

\section{SIMPULAN}

Berdasarkan hasil penelitian mayoritas bidan praktik mandiri ( $50 \%$ ) belum menerapkan pendokumentasian dengan metode S-O-A-P dalam asuhan kebidanannya. Hal ini dapat disimpulkan bahwa bidan praktik mandiri belum menjalankan aturan yang tertuang dalam Kepmenkes no 938 tahun 2007 tentang standar asuhan kebidanan.

\section{SARAN}

untuk dapat mengadakan profesi bidan pendokumentasian bagi para bidan dan melakukan supervisi terkait penerapan pendokumentasian asuhan kebidanan dengan metode S-O-A-P. Diharapkan bidan praktik mandiri dapat melakukan pencatatan dalam setiap pelayanan kebidanan yang dilakukan, agar tercapai pelayanan yang berkualitas.

\section{DAFTAR PUSTAKA}

Anggraini, D. D., Sari, M. H. N., Ritonga, F., Yuliani, M., Wahyuni, W., Amalia, R., ... \& Winarso, S. P. (2020). Konsep Kebidanan. Yayasan Kita Menulis.

Aisa S, dkk. (2018). Panduan Penulisan Catatan SOAP dalam Pendokumentasian Kebidanan. NUha Medika.
Anita, W. (2016). The implementation of documentation by midwives in Pekanbaru. Kesmas, 13(1), 43-47. https://doi.org/10.21109/kesmas.v13i1.1403

Ariyanti, D. F. (2010). Analisis kualitas pelayanan antenatal oleh bidan di Puskesmas di Kabupaten Purbalingga (Doctoral dissertation, UNIVERSITAS DIPONEGORO).

Bensley, R. J., \& Brookins-Fisher, J. (2009). Metode Pendidikan Kesehatan Msyarakat. EGC.

Haslinda. (2017). Penerapan Model Pendokumentasian Asuhan Terintegrasi Di RSUD Haji Makassar Provinsi Sulawesi Selatan. http://repositori.uinalauddin.ac.id/id/eprint/4698

Kepmenkes. (2007). Kepmenkes No. 938/Menkes/SKVIII/2007 STANDAR ASUHAN KEBIDANAN MENTERI KESEHATAN REPUBLIK INDONESIA.

Kepmenkes. (2020). Kepmenkes NOMOR HK.01.07/MENKES/320/2020 TENTANG STANDAR PROFESI BIDAN. 2017(1), 1-9.

Mertasari, L., \& Sugandini, W. (2021). Aktualisasi Pendokumentasian Asuhan Kebidanan dengan Metode Soap pada Praktek Mandiri Bidan (PMB). International Journal of Natural Science and Engineering, 5(1).

Palifiana, D. A. (2016). Hubungan pendidikan Bidan dengan penerapan pendokumentasian asuhan kebidanan pada Bidan Praktik Mandiri di Kabupaten Bantul. 412-415.

PUSPITASARI, D. (2019). Pelaksanaan Dokumentasi Asuhan Kebidanan Terhadap Perlindungan Hukum Pasien pada Bidan Praktik Mandiri (Studi di Kabupaten Cilacap). Jurnal Idea Hukum, 5(1).

Ramadanty, y. (2018). Gambaran tentang penyimpanan dokumen pelayanan kebidanan sebagai akuntabilitas bidan di praktik mandiri bidan wilayah kabupaten bandung 2018.

Siyoto, S., \& Sodik, M. A. (2015). Dasar metodologi penelitian. Literasi Media Publishing.

Sumiati, e. (2018). Gambaran tentang isi pendokumentasian pelayanan kebidanan sebagai bukti akuntabilitas bidan di praktik mandiri bidan wilayah kabupaten bandung 2018.

Wildan M, A. A. (2008). Dokumentasi Kebidanan Google Books. Salemba Medika. 